\title{
Characterization of Genetic Diversity of Rice Genotypes Showing Resistance to Rice Leaf Folder, Cnapholocrocis medinalis Using SSR Markers
}

\author{
N. Kamakshi ${ }^{1}$, P. Rajasekhar ${ }^{2}$, G. Ramachandra Rao $^{3}$, P. Anil Kumar ${ }^{3}$ and P.N. Harathi \\ ${ }^{1}$ Regional Agricultural Research Station, Nandyal, Kurnool (Dist), A.P.-518503, India \\ ${ }^{2}$ Agricultural Research Station, Nellore, SPSR Nellore (Dist), A.P. -524301, India \\ ${ }^{3}$ Agricultural College, Bapatla, Guntur (Dist.), A.P. - 522101, India \\ ${ }^{4}$ Agricultural Research Station, Nellore, SPSR Nellore (Dist), A.P. -524301, India \\ *Corresponding author
}

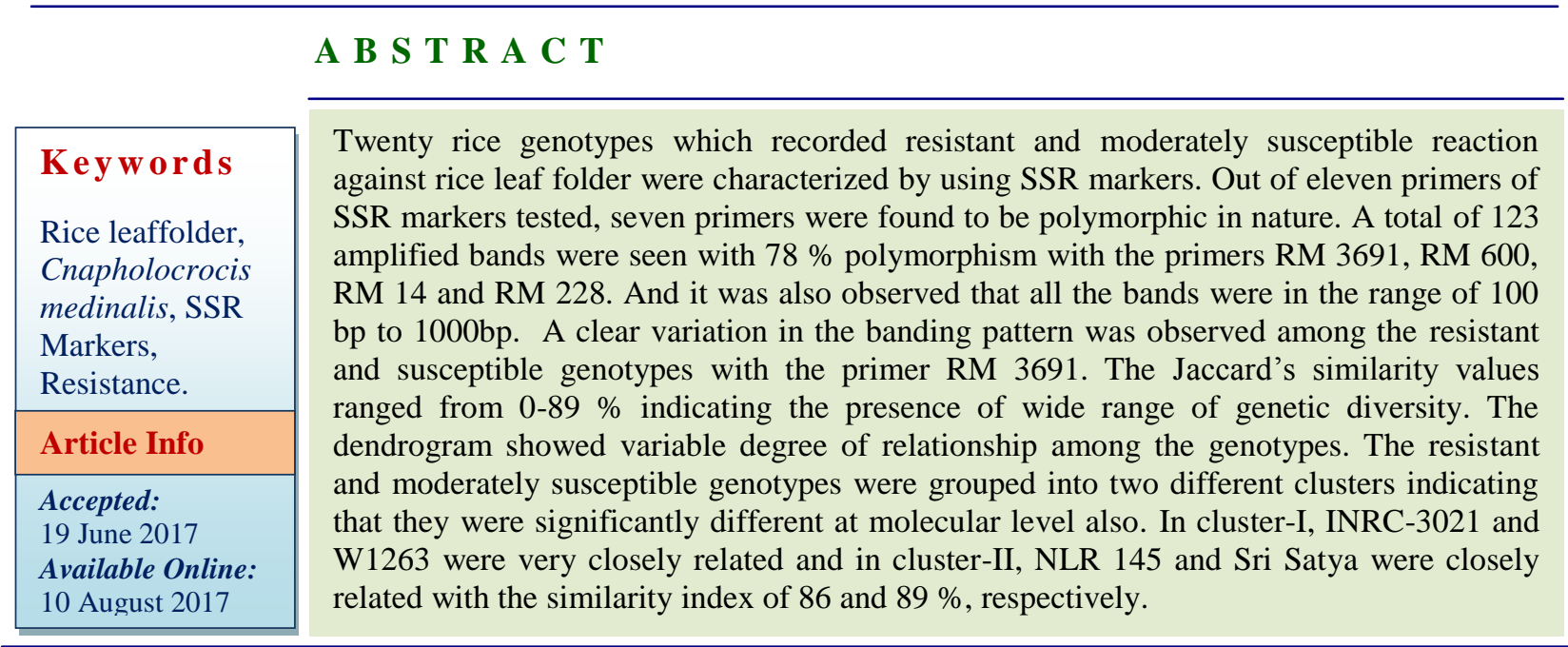

\section{Introduction}

Rice (Oryza sativa L.) is one of the most significant cereals and is the staple food for more than 2 billion people, mostly in developing countries. India leads the world in rice with 44.06 million hectares with a production of 105.32 million tonnes, but productivity is only $75 \%$ of the world average of 4.02 tonnes ha $^{-1}$ (Directorate of Rice Development, 2014). Insect pests are the major constraints in enhancing rice productivity which cause 20-30 \% loss, besides diseases and weeds (Behura et al., 2011). Nearly 300 spp. of insect pests are attacking the paddy crop at various stages and among them only 23 species cause notable damage (Pasalu and Katti, 2006).

The Rice leaffolder, Cnaphalocrocis medinalis earlier considered as a minor pest has gained the status of major pest with the wide spread of high yielding rice varieties, changes in the cultural practices, multiple cropping patterns, reduced genetic variability of high yielding rice varieties and application of high levels of nitrogenous fertilizers (Nanda et al., 2000). For managing the pest, host plant resistance is one of the components in Integrated Pest Management (IPM) in 
which identification of phenotypic, bio chemical and molecular markers are included. Among the different classes of molecular markers, SSR markers are often chosen as the preferred markers for a variety of applications in breeding because of their multi-allelic nature, co-dominant inheritance, relative abundance and extensive genome coverage (Gupta and Varshney, 2000). It is essential to know the genetic diversity at molecular level for developing a resistant variety among the available genotypes. Keeping these points in view, present study was undertaken with the objective of estimating genetic diversity in rice genotypes, which showed resistance to rice leaf folder in field level, using SSR markers.

\section{Materials and Methods}

\section{Field screening of rice genotypes against Rice leaf folder}

Fifty rice genotypes collected from different locations were raised under natural field conditions at ARS, Nellore during kharif 2009 and 2010. Two rows of 25 hills in each row were transplanted for each entry with two replications. TN1 was used as susceptible check. All the recommended agronomic practices except leaf folder protection measures were adopted during the experiment. Observations on leaf folder damage were recorded on five randomly selected plants in each genotype at 25, 40 and 70 DAT. Per cent damage was calculated by using the following formula.

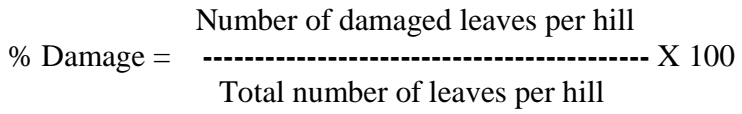

Based on the mean $\%$ damage during two seasons, Rice genotypes were categorized into Highly Resistant (0\%), Resistant (1-15\%), Moderately Resistant (16-30\%), Moderately susceptible (31- $50 \%$ ), Susceptible (51-75\%) and Highly Susceptible ( $>75 \%$ ) by following
IRRI Standard Evaluation System (SES) for rice,1980. A total of twenty rice genotypes which exhibited resistant and moderately susceptible reaction against rice leaf folder were characterized using SSR markers.

\section{DNA extraction and SSR marker analysis}

The total DNA of each rice genotypes was extracted from leaves using the modified CTAB method (Murray and Thomson, 1980). Then the quality and quantity of DNA was verified by spectrophotometrically and also by using Nano drop procedure.

PCR was performed in $25 \mu$ of reaction mixture using $2.5 \mu \mathrm{l}$ of $10 \mathrm{X}$ PCR reaction buffer, $2.5 \mu \mathrm{l}$ of $25 \mathrm{mM} \mathrm{MgCl} 2,0.5 \mu \mathrm{l}$ of 10 $\mathrm{mM}$ dNTPs, 2 pmol of each forward and reverse primer, $0.2 \mu 1$ of $3 \mathrm{U} / \mu 1$ of Taq DNA polymerase (Genei, Bangalore), 100-200ng of genomic DNA and $18.9 \mu 1$ sterile distilled water. The amplification was performed in a PCR machine (Eppendorf Programmable thermal controller, Hamburg, Germany). PCR amplifications profile was with initial denaturation of DNA at $94^{\circ} \mathrm{C}$ for $5 \mathrm{~min}$ followed by 35 cycles of amplification at $94^{\circ} \mathrm{C}$ for $1 \mathrm{~min}$ with annealing temperatures of $54-60^{\circ} \mathrm{C}$ for $1 \mathrm{~min}$, extension step at $72^{\circ} \mathrm{C}$ for $2 \mathrm{~min}$ and final extension was made at $72^{0} \mathrm{C}$ for $5 \mathrm{~min}$. Then the PCR product was finally kept at $4^{0} \mathrm{C}$ for electrophoresis. The annealing temperatures were optimized individually for each primer (Table 2). Before loading PCR Products in vertical gels, amplification was checked on $2.0 \%$ agarose gel. Based on agarose gel electrophoresis of amplification product, the separation of DNA fragments was carried out using 9\% nondenaturing polyacrylamide gel electrophoresis (PAGE).

After PCR amplification, $3 \mu 1$ of bromo phenol blue dye was added to $25 \mu$ reaction mixture. Then $25 \mu 1$ of this reaction mixture was loaded by using eppendorf micropipette on each lane 
of 13-track gel of 9\% non-denaturing PAGE and as the base pair marker, 50kb DNA ladder was loaded on one corner of the gel. Composition of $30 \mathrm{ml}$ of $9 \%$ PAGE gel was $16.5 \mathrm{ml}$ of distilled water, $4.5 \mathrm{ml}$ of $10 \mathrm{X}$ TBE, $9 \mathrm{ml}$ of acrylamide-methylbisacrylamide

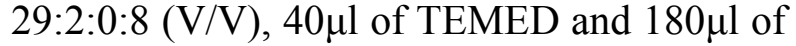
$10 \%$ APS (ammonium per sulphate). Electrophoresis was done at 100 volts for 3-4 hours in $1 \mathrm{X}$ TBE running buffer. PCR products were visualized by using silver staining protocol (Kolodny, 1984).

The banding pattern was observed under white lamp trans-illuminator using gel documentation system (Alpha Innotech, USA) in an auto exposure mode and the gel picture was documented. Clearly resolved, un ambiguous bands were scored visually for their presence or absence with each primer. The scores were obtained in the form of matrix with ' 1 ' and ' 0 ', which indicates the presence and absence of bands in each variety respectively. The data matrix thus generated was used to calculate Jaccard's similarity coefficient for each pair-wise comparison. The coefficients were calculated Insilico following Jaccard (1908), using the following formula.

Similarity coefficient $=\stackrel{a}{n}$

where,

$\mathrm{a}=$ Number of matching bands for each pair of comparisons

$\mathrm{n}=$ Total number of bands observed in two samples.

The similarity co-efficients were subjected to Unweighted Pair-Group Method of Arithmetical averages (UPGMA) cluster analysis to for grouping the genotypes based on their overall similarities. Statistical Package for Social Sciences (SPSS) package was used for the cluster analysis and subsequent dendrogram preparation.

\section{Results and Discussion}

Field evaluation of rice genotypes against rice leaf folder

The mean percent leaf damage (kharif 2009 and 2010) due to leaf folder in fifty rice genotypes ranged from 11.4 to 37.4 . The lowest damage was recorded in Jhitpiti $(11.4 \%)$ and highest damage was observed in NLR-145 (37.4\%). Based on overall leaf folder percent damage during two years, the genotypes were categorized into various groups according to Standard Evaluation System for Rice given by IRRI, 1980. Out of 50 genotypes of rice, ten genotypes were found resistant, thirty were moderately resistant and ten genotypes showed moderately susceptible reaction against leaf folder. A total of twenty rice genotypes which exhibited extreme level resistant and moderately susceptible reaction against rice leaf folder were evaluated using SSR markers (Table 1).

\section{Characterization through SSR markers}

\section{Primer selection and survey}

In the amplification of genomic DNA of the twenty selected rice genotypes using 11 primers of SSR markers (Table 3), ten primers given reproducible and scorable bands with high percentage of polymorphism. PCR amplification with these primers was done twice before scoring for presence or absence of bands.

\section{Banding pattern}

With PAGE gel analysis among 10 primers, seven primers were found to be polymorphic. A total of 123 amplified bands were seen with $70.8 \%$ polymorphism. The number of amplified fragments ranged from 2 to 33 with an average of 8.72 per primer (Table 3 ). 
Herrera et al., (1999) used a set of 48 microsatellites to assess the genetic diversity of 11 Venezuelan rice cultivars and a total of 203 alleles were detected and the number of alleles per marker ranged from 2 to 9 , with an average of 4.23 .

The maximum polymorphism in PCR reaction was observed with the primers RM 3691, RM 600, RM 14 and RM 228 and these showed
$100 \%$ polymorphism as all the bands were polymorphic with size ranging from $100 \mathrm{bp}$ to $1000 \mathrm{bp}$. The primers RM-495, RM 5380 and RM -6867 showed $0 \%$ polymorphism as all were monomorphic. Selvaraju et al., (2007) reported that the primers RM 495, RM 600, RM 14 and RM 3691 were significantly associated and alleles amplified with rice leaf folder resistance.

Table.1 The selected rice genotypes (20) which were resistant and moderately susceptible to Rice leaf folder

\begin{tabular}{|c|l|c|c|c|l|c|c|}
\hline \multicolumn{4}{|c|}{ Resistant Genotypes } & \multicolumn{5}{c|}{ Moderately Susceptible Genotypes } \\
\hline $\begin{array}{c}\text { S. } \\
\text { No }\end{array}$ & Genotype Name & $\begin{array}{c}\text { \% Leaf } \\
\text { Damage }\end{array}$ & $\begin{array}{c}\text { Damage } \\
\text { Rating }\end{array}$ & S.No & Genotype Name & $\begin{array}{c}\text { \% Leaf } \\
\text { Damage }\end{array}$ & $\begin{array}{c}\text { Damage } \\
\text { Rating }\end{array}$ \\
\hline 1 & NLR 3010 & 14.11 & 1 & 11 & NLR 20127 & 32.06 & 5 \\
\hline 2 & NLR 40059 & 14.21 & 1 & 12 & NLR 20128 & 32.63 & 5 \\
\hline 3 & RP-2068-18-3-5 & 12.02 & 1 & 13 & NLR 33636-4 & 36.69 & 5 \\
\hline 4 & Jhitpiti & 11.40 & 1 & 14 & NLR 33671-1 & 36.79 & 5 \\
\hline 5 & INRC-202 & 13.15 & 1 & 15 & NLR 33671-7 & 32.17 & 5 \\
\hline 6 & INRC-1997 & 14.30 & 1 & 16 & RP-4688-53-2-1255 & 36.02 & 5 \\
\hline 7 & INRC-3021 & 13.37 & 1 & 17 & TN 1 & 37.16 & 5 \\
\hline 8 & W- 1263 & 14.43 & 1 & 18 & IR -36 & 33.36 & 5 \\
\hline 9 & LF 293 & 14.39 & 1 & 19 & NLR 145 & 37.39 & 5 \\
\hline 10 & LF 333 & 13.24 & 1 & 20 & Sri satya & 31.95 & 5 \\
\hline
\end{tabular}

Table.2 List of SSR primers selected for DNA amplification

\begin{tabular}{|c|c|c|c|c|}
\hline S.No & $\begin{array}{c}\text { Primer } \\
\text { Name }\end{array}$ & Forward primer & Reverse primer & $\begin{array}{c}\text { Annealing } \\
\text { temp }\left({ }^{0} \mathrm{C}\right)\end{array}$ \\
\hline 1 & RM495 & AATCCAAGGTGCAGAGATGG & CAACGATGACGAACACAACC & 58 \\
\hline 2 & RM600 & AAACGTGTGTTAGCCTGTTAGG & CATATGCTAGTGGTGCTAGCG & 58 \\
\hline 3 & RM576 & GGACGGCGAGTTCATAAATAG & CTTGATGGGATAAAAGCATCAG & 54 \\
\hline 4 & RM3412 & AAAGCAGGTTTTCCTCCTCC & CCCATGTGCAATGTGTCTTC & 54 \\
\hline 5 & RM14 & CCGAGGAGAGGAGTTCGAC & GTGCCAATTTCCTCGAAAAA & 58 \\
\hline 6 & RM5100 & AAAAGAGTCTCTTCTCTCT & AGGACACATACTGTGTATAA & 54 \\
\hline 7 & RM5405 & CACTCTCACACTCACCAGCG & GTCGTCTCGCTCTCATCTCC & 60 \\
\hline 8 & RM5380 & CCACCCTGTTCATCTCGC & ATGGCGATACCACCACTCTC & 60 \\
\hline 9 & RM3691 & GCTGATGGTCAAAGATCAGG & ATGTGTCTGCTGGCACAGAG & 58 \\
\hline 10 & RM6867 & AGAGAGCACAATCGGAGTCG & GCAGCAGCAACAAGATGTTC & 58 \\
\hline 11 & RM228 & CTGGCCATTAGTCCTTGG & GCTTGCGGCTCTGCTTAC & 58 \\
\hline
\end{tabular}


Table.4 Jaccard's similarity coefficient of twenty selected genotypes of rice based on polymorphism obtained with 10 primers

\begin{tabular}{|c|c|c|c|c|c|c|c|c|c|c|c|c|c|c|c|c|c|c|c|c|}
\hline & $\begin{array}{l}\text { NLR } \\
3010 \\
\end{array}$ & $\begin{array}{l}\text { NLR } \\
4005 \\
9 \\
\end{array}$ & $\begin{array}{l}\text { RP- } \\
206 \\
8- \\
18- \\
3-5 \\
\end{array}$ & $\begin{array}{l}\text { Jhitp } \\
\text { iti }\end{array}$ & $\begin{array}{l}\text { INR } \\
\text { C- } \\
202 \\
\end{array}$ & $\begin{array}{l}\text { INR } \\
\text { C- } \\
1997 \\
\end{array}$ & $\begin{array}{l}\text { INR } \\
\text { C- } \\
3021 \\
\end{array}$ & $\begin{array}{l}\text { W- } \\
1263 \\
\end{array}$ & $\begin{array}{l}\text { LF } \\
293 \\
\end{array}$ & $\begin{array}{l}\text { LF } \\
333 \\
\end{array}$ & $\begin{array}{l}\text { NLR } \\
2012 \\
7 \\
\end{array}$ & $\begin{array}{l}\text { NLR } \\
2012 \\
8 \\
\end{array}$ & $\begin{array}{l}\text { NLR } \\
3363 \\
6-4 \\
\end{array}$ & $\begin{array}{l}\text { NLR } \\
33671 \\
-1 \\
\end{array}$ & $\begin{array}{l}\text { NLR } \\
33671- \\
7 \\
\end{array}$ & $\begin{array}{l}\text { RP- } \\
4688- \\
53-2- \\
1255 \\
\end{array}$ & TN 1 & $\begin{array}{l}\text { IR- } \\
36 \\
\end{array}$ & $\begin{array}{l}\text { NLR } \\
145 \\
\end{array}$ & $\begin{array}{l}\text { Sri } \\
\text { Sathya } \\
\end{array}$ \\
\hline NLR 3010 & 1.00 & & & & & & & & & & & & & & & & & & & \\
\hline NLR 40059 & 0.20 & 1.00 & & & & & & & & & & & & & & & & & & \\
\hline $\begin{array}{l}\text { RP-2068- } \\
18-3-5 \\
\end{array}$ & 0.09 & 0.07 & 1.00 & & & & & & & & & & & & & & & & & \\
\hline Jhitpiti & 0.13 & 0.22 & 0.22 & 1.00 & & & & & & & & & & & & & & & & \\
\hline INRC-202 & 0.12 & 0.21 & 0.15 & 0.32 & 1.00 & & & & & & & & & & & & & & & \\
\hline INRC-1997 & 0.06 & 0.10 & 0.22 & 0.12 & 0.32 & 1.00 & & & & & & & & & & & & & & \\
\hline INRC-3021 & 0.06 & 0.11 & 0.31 & 0.13 & 0.27 & 0.69 & 1.00 & & & & & & & & & & & & & \\
\hline W -1263 & 0.06 & 0.11 & 0.31 & 0.17 & 0.22 & 0.59 & 0.86 & 1.00 & & & & & & & & & & & & \\
\hline LF 293 & 0.07 & 0.06 & 0.46 & 0.14 & 0.18 & 0.25 & 0.41 & 0.41 & 1.00 & & & & & & & & & & & \\
\hline NLR 20127 & 0.00 & 0.00 & 0.00 & 0.00 & 0.00 & 0.00 & 0.00 & 0.00 & 0.00 & 0.15 & 1.00 & & & & & & & & & \\
\hline NLR 20128 & 0.00 & 0.06 & 0.00 & 0.00 & 0.00 & 0.00 & 0.00 & 0.00 & 0.00 & 0.05 & 0.31 & 1.00 & & & & & & & & \\
\hline $\begin{array}{l}\text { NLR } \\
33636-4\end{array}$ & 0.00 & 0.00 & 0.00 & 0.04 & 0.04 & 0.00 & 0.00 & 0.00 & 0.00 & 0.05 & 0.41 & 0.40 & 1.00 & & & & & & & \\
\hline $\begin{array}{l}\text { NLR } \\
33671-1\end{array}$ & 0.00 & 0.00 & 0.00 & 0.04 & 0.04 & 0.00 & 0.00 & 0.00 & 0.00 & 0.04 & 0.47 & 0.38 & 0.67 & 1.00 & & & & & & \\
\hline $\begin{array}{l}\text { NLR } \\
33671-7\end{array}$ & 0.00 & 0.05 & 0.00 & 0.04 & 0.03 & 0.00 & 0.00 & 0.00 & 0.00 & 0.04 & 0.29 & 0.26 & 0.50 & 0.47 & 1.00 & & & & & \\
\hline $\begin{array}{l}\text { RP-4688- } \\
53-2-1255\end{array}$ & 0.00 & 0.00 & 0.00 & 0.03 & 0.03 & 0.00 & 0.00 & 0.00 & 0.00 & 0.04 & 0.27 & 0.19 & 0.27 & 0.45 & 0.41 & 1.00 & & & & \\
\hline TN 1 & 0.00 & 0.00 & 0.00 & 0.04 & 0.04 & 0.00 & 0.00 & 0.00 & 0.00 & 0.00 & 0.13 & 0.10 & 0.18 & 0.23 & 0.21 & 0.36 & 1.00 & & & \\
\hline IR-36 & 0.00 & 0.00 & 0.00 & 0.04 & 0.04 & 0.00 & 0.00 & 0.00 & 0.00 & 0.00 & 0.18 & 0.15 & 0.18 & 0.23 & 0.16 & 0.36 & 0.33 & 1.00 & & \\
\hline NLR 145 & 0.00 & 0.00 & 0.00 & 0.00 & 0.00 & 0.00 & 0.00 & 0.00 & 0.00 & 0.00 & 0.05 & 0.06 & 0.05 & 0.05 & 0.05 & 0.09 & 0.29 & 0.38 & 1.00 & \\
\hline Sri Sathya & 0.00 & 0.00 & 0.00 & 0.00 & 0.00 & 0.00 & 0.00 & 0.00 & 0.00 & 0.00 & 0.05 & 0.06 & 0.05 & 0.05 & 0.04 & 0.09 & 0.35 & 0.35 & 0.89 & 1.00 \\
\hline
\end{tabular}


Table.3 Allelic variation of SSR primers used for DNA amplification of selected rice genotypes for leaf folder resistance

\begin{tabular}{|c|c|c|c|c|c|}
\hline S.No. & Primer Name & $\begin{array}{c}\text { Total No. of } \\
\text { alleles }\end{array}$ & $\begin{array}{c}\text { No. of polymorphic } \\
\text { alleles }\end{array}$ & $\begin{array}{c}\text { Amplification } \\
\text { size (bp) }\end{array}$ & $\begin{array}{c}\% \\
\text { Polymorphism }\end{array}$ \\
\hline 1 & RM495 & 8 & 0 & 190 & 0 \\
\hline 2 & RM600 & 18 & 18 & 285 & 100 \\
\hline 3 & RM576 & 6 & 6 & Non distinct & 100 \\
\hline 4 & RM3412 & 0 & 0 & Non distinct & 0 \\
\hline 5 & RM14 & 14 & 14 & 200 & 100 \\
\hline 6 & RM5100 & 10 & 10 & 370 & 100 \\
\hline 7 & RM5405 & 12 & 2 & 250 & 16.7 \\
\hline 8 & RM5380 & 3 & 0 & Non distinct & 0 \\
\hline 9 & RM3691 & 33 & 33 & 250 & 100 \\
\hline 10 & RM6867 & 6 & 0 & 200 & 0 \\
\hline 11 & RM228 & 13 & 13 & 115 & 100 \\
\hline & Total & 123 & 96 & & 78.05 \\
\hline & Average & & 8.72 & & \\
\hline
\end{tabular}

Fig.1 Gel profile showing the amplification of SSR primer RM 3691 with 20 selected rice genotypes

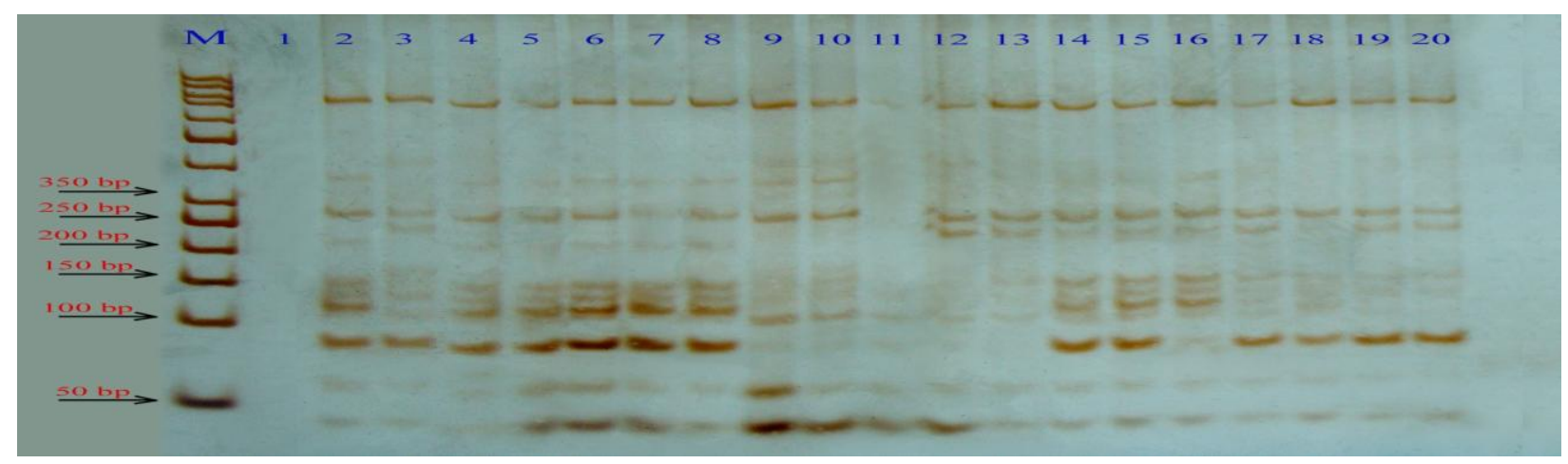

Fig.2 Gel profile showing the amplification of SSR primer RM 14 with 20 selected rice genotypes

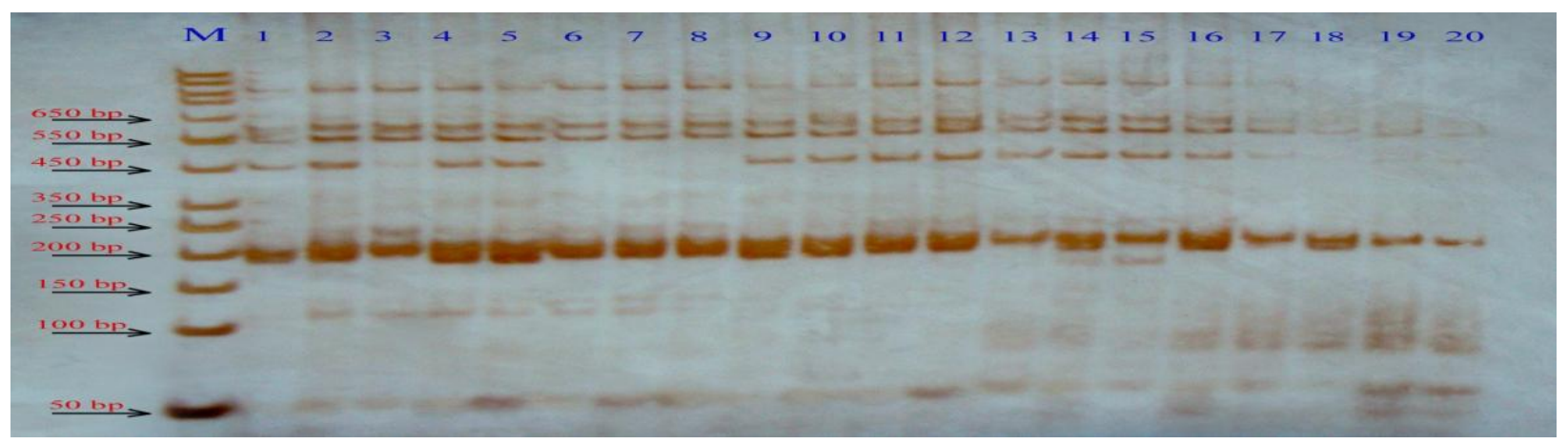

Note: The numeric number above the lane indicates the genotype number as in Table 1 and $\mathrm{M}$ indicates the Marker $50 \mathrm{~kb}$ 
Fig.3 Dendrogram depicting variation among rice genotypes based on SSR analysis

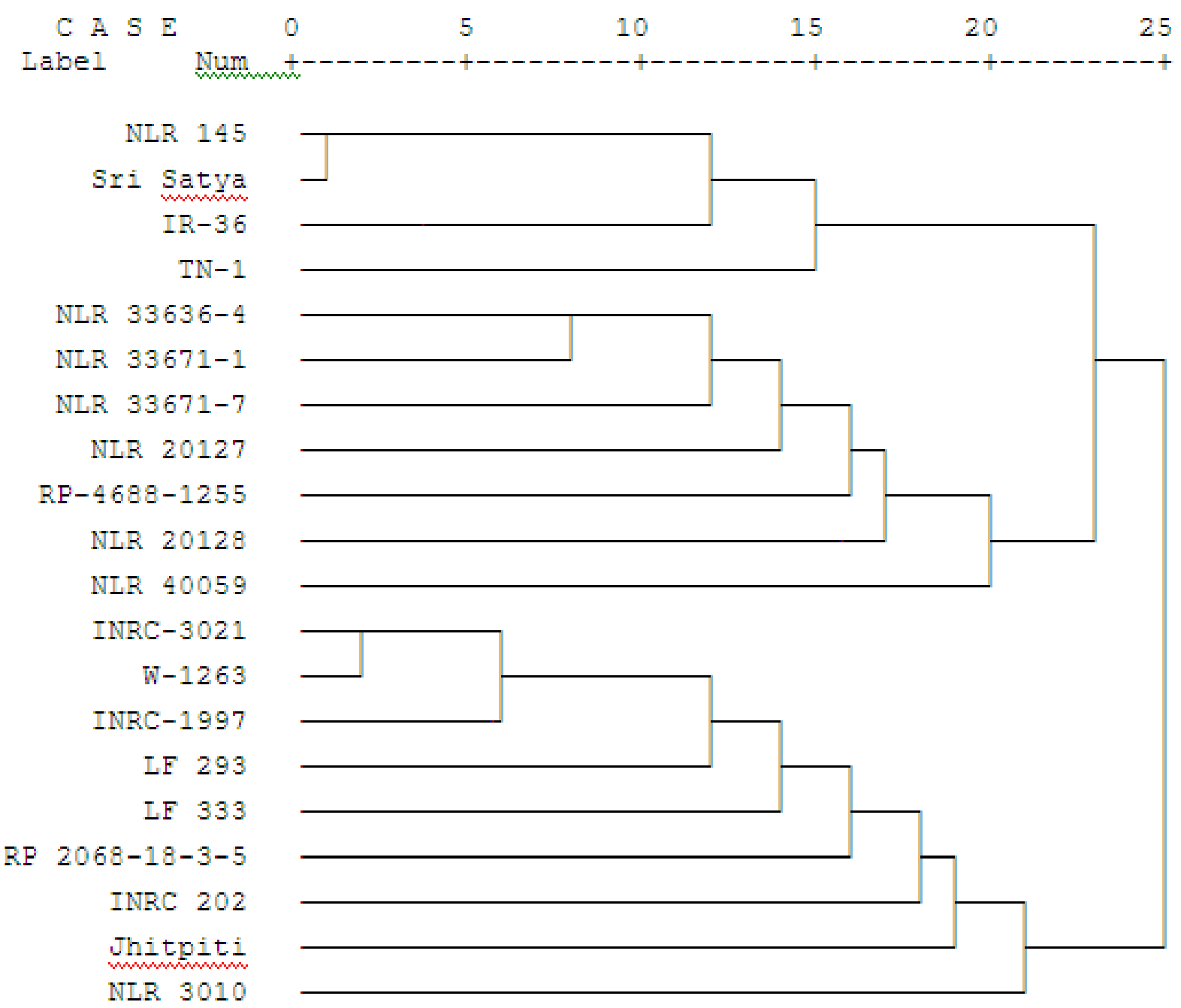

A clear variation in the banding pattern was observed among resistant and moderately susceptible genotypes with the primer RM 3691. In majority of genotypes, a maximum number of 33 amplified bands at $100 \mathrm{bp}$ and at $250 \mathrm{bp}$ size were present (Fig. 1). In the profile of RM 14, a clear variation in banding pattern was observed with 14 scorable polymorphic bands present at $200 \mathrm{bp}$ and 450 bp size (Fig. 2). In the profile of remaining primers there was a clear variation among different genotypes. The similarity index values ranged from 0 to $89 \%$ indicating the presence of wide range of genetic diversity at molecular level among the genotypes, tested for leaf folder resistance (Table 3).

\section{Cluster analysis}

Similarity coefficients were subjected to Unweighted Pair Group Method on Arthematic average (UPGMA) using paired matrix values and are presented in figure 3. The dendrogram exhibited variable degree of relationship among the genotypes studied and indicated two major clusters. The ten resistance genotypes and other ten moderately susceptible genotypes to rice leaf folder were grouped into two different clusters indicating that they are significantly different at molecular level and among cluster-I, INRC-3021 and W1263 were very closely related and in cluster-II, NLR 145 and Sri 
Satya were closely related with the similarity index of 86 and $89 \%$, respectively.

In conclusion, results revealed that 70.8 percent polymorphism existed among twenty genotypes using SSR markers indicated the presence of wide range of genetic diversity at molecular level. Dendogram clearly distinguished the resistant and moderately susceptible genotypes for rice leaf folder, Cnapholocrocis medinalis by clearly forming into two different clusters indicating that they are significantly different at molecular level and were correlated with the field performance.

In future, Correlation studies may be conducted among different genotypes with the data of parentage for drawing more conclusions.

\section{Acknowledgements}

We are grateful to the staff of Regional Agricultural Research Station, Tirupati for their help to carry out the molecular work especially in screening the germplasm using SSR markers at Institute of Frontier Technologies.

\section{References}

Behura, N., Sen, P., Kar, M.K. 2011. Introgression of yellow stem borer (Scirpophaga incertulus) resistance gene into cultivated rice (Oryza sp.) from wild spp. Indian J. Agri. Sci., 81: 359-362.

Directorate of Rice Development. 2014. Status paper on Rice. 151. http://drd.dacnet.nic.in/
Gupta, P.K. and Varshney, R.K. 2000. The development and use of microsatellite markers for genetic analysis and plant breeding with emphasis on bread wheat. Euphytica, 113: 163-185

Herrera, T.G., Duque, D.P., Almeida, I.P., Nunez, G.T., Pieters, A.J., Martinez, C.P and Tohme, J.M. 1999. Assessment of genetic diversity in Venezuelan rice cultivars using simple sequence repeats markers. Electronic J. Biotechnol., 11(5): 1-6

International Rice Research Institute. Standard Evaluation System for Rice. 1980. III edition. IRRI, Los Banos, Philippines, 123.

Jaccard, P. 1908. Nouvelles recherches surla distribution florale. Bulletin de la Société vaudoise des sciences naturelles, 44: 223270.

Kolodny, G.M. 1984. An improved method for increasing the resolution and sensitivity of silver staining of nucleic acid bands in polyacrylamide gels. Anal. Biochem., 138: 66-67.

Murray, M. and Thompson, W. 1980. The isolation of high weight plant DNA. Nucleic Acids Res., 8: 4321-4325.

Nanda, U.K., Mahapatro, G.K., Sahoo, A and Mahapatra, S.C. 2000. Rice Leaffolder: Integrated neem derivatives in its management. Pestol., 24(7): 31-34.

Pasalu, I.C., Katti, G., 2006. Advances in eco friendly approaches in rice IPM. J. Rice Res., 1(1): 83-90.

Selvaraju, K., Shanmugasundaram, P., Mohankumar, S., Asaithambi, $\mathrm{M}$ and Balasaraswathi, R. 2007. Detection of quantitative trait locus for leaffolder resistance in rice on linkage group 1 based on damage score and flag leaf width. Euphytica, 157: 35-43.

\section{How to cite this article:}

Kamakshi, N., P. Rajasekhar, G. Ramachandra Rao, P. Anil Kumar and Harathi, P.N. 2017. Characterization of Genetic Diversity of Rice Genotypes Showing Resistance to Rice Leaf Folder, Cnapholocrocis medinalis Using SSR Markers. Int.J.Curr.Microbiol.App.Sci. 6(8): 2171-2178. doi: https://doi.org/10.20546/ijcmas.2017.608.257 